\title{
Dosage Form for Solution
}

National Cancer Institute

\section{Source}

National Cancer Institute. Dosage Form for Solution. NCI Thesaurus. Code C60927.

A substance intended for administration as a solution. 